\title{
RANCANG BANGUN PROTOTIPE SISTEM KENDALI IRON REMOVAL FILTER (IRF) PADA UNIT PENGOLAHAN AIR BERSIH BERBASIS PLC
}

\author{
Kukuh Karyadi ${ }^{1}$, Jatmiko Endro Suseno ${ }^{2)}$ \\ ${ }^{1)}$ PT. Badak LNG (Persero) \\ ${ }^{2)}$ Program Studi Sarjana Terapan Teknologi Rekayasa Otomasi \\ Sekolah Vokasi, Universitas Diponegoro
}

\begin{abstract}
Kukuh Karyadi, Jatmiko Endro Suseno in this paper explain that Water is a necessity of life that is very important for mankind. The availability of clean water has been sought to be fulfilled in various ways. One of them is by making a clean water treatment plant that can process water that is not yet suitable for consumption to be more feasible and ready to be consumed for everyday life. The operation of water treatment plant is still manually operated such as in the Iron Removal Filter (IRF) control system so that the processing is not easy to operate. To facilitate the operation of a clean water treatment unit, a control system based on a Programmable Logic Controller (PLC) is created on the Iron Removal Filter (IRF) processing unit.

Control system consisting of PLC, relay circuit, power supply and Human Machine Interface (HMI), works to control the clean water processing unit including controlling the process on the IRF automatically. Also made a prototype of a water treatment plant consisting of an aerator unit, an IRF unit, a storage tank, several pumps and several control valves to be controlled by the control system in operation. The control system uses PLC as a control center because PLC is a controller that is simple, easy to program and very reliable as already widely used in the industrial world. The PLC brand used is Omron because it is cheap, reliable and has software named $C X$-Programmer which is easy in programming. The control system uses laptop computer as an HMI in the operation. HMI uses VTScada software and is connected to a PLC using OPC CX-Server software. The control system that is made can control the clean water processing unit in the form of a prototype. Operation on HMI is so easy and has a very attractive appearance. So it is highly recommended to be used in the actual clean water treatment unit.
\end{abstract}

Keywords: water treatment plant; iron removal filter; PLC; HMI; OPC Server;

\section{PENDAHULUAN}

\section{Latar Belakang}

Dalam dunia industri, berbagai kondisi suatu proses diatur oleh suatu sistem yang disebut sistem kendali. Sistem kendali merupakan sebuah sistem yang terdiri atas satu atau beberapa peralatan yang berfungsi untuk mengendalikan sistem lain yang berhubungan dengan sebuah proses [3]. PLC adalah suatu jenis komputer yang digunakan untuk aplikasi sistem kendali di dunia industri dan komersial. PLC bekerja berdasarkan kontak tertutup dan terbuka (open/close contact). Dengan manusia menanamkan suatu logika yang diprogramkan kedalamnya. Program logika tersebut dihubungkan ke input dan output-nya menggunakan relai. Programnya pun dapat ditulis atau dipasang dengan berbagai cara ataupun metoda [4]. Salah satu sistem proses yang dapat dikendalikan oleh PLC adalah sebuah unit pengolah air bersih. Air bersih merupakan kebutuhan hidup yang sangat penting bagi umat manusia. Dibuatnya unit pengolah air bersih bertujuan untuk dapat mengolah air yang belum layak dikonsumsi menjadi lebih layak dan siap dikonsumsi untuk kehidupan sehari-hari. Unit ini memiliki serangkaian filter air yang dinamai Iron Removal Filter (IRF). Sesuai namanya, filter ini berfungsi untuk menyaring unsur besi/iron $(\mathrm{Fe})$ yang masih banyak terkandung di dalam air sumur (air baku).

\section{Tujuan}

Tujuan yang hendak dicapai dari penelitian ini adalah sebagai berikut:

- Mengetahui sistem kerja dan pembuatan unit pengolah air bersih pada bagian IRF.

- Memahami cara memprogram PLC sebagai pusat sistem kendali dalam untuk suatu unit pengolah air bersih dan cara memprogram SCADA sebagai HMI yang merupakan media operator untuk mengoperasikan unit pengolah air bersih.

- Membuat unit pengolah air bersih yang dapat dikendalikan secara otomatis.

Batasan Masalah Pada penelitian ini masalah dibatasi pada halhal, diantaranya sebagai berikut :

- Prinsip kerja sistem kendali unit pengolah air bersih berbasis PLC Omron CP1E-E30 dengan perangkat lunak HMI VTScada.

- Penggunaan relai sebagai driver output PLC.

- Sistem kendali pengolah air bersih berbasis PLC yang dibuat mengacu kepada model Plant \#48 Community Water Treatment Plant yang berada di kilang Badak LNG Bontang. 


\section{PENGOLAHAN AIR BERSIH}

Unit pengolah air bersih mengambil air baku yang bersumber dari air tanah sehingga memiliki kekurangan kandungan oksigen. Untuk itu, harus dilakukan proses pemberian udara atau oksigen yang cukup. Proses pemberian udara ini disebut proses "Aerasi" dan dilakukan oleh alat yang disebut dengan "Aerator". [1]

Penyaringan terhadap air baku untuk menyaring berbagai mineral yang tidak dikehendaki kemudian dilakukan. Proses penyaringan ini dilakukan oleh bejana penyaring atau biasa disebut dengan filter. Kemudian air yang telah bersih ditampung ke dalam tangki penampungan untuk kemudian dapat didistribusikan ke berbagai tempat untuk dapat dikonsumsi. [1]

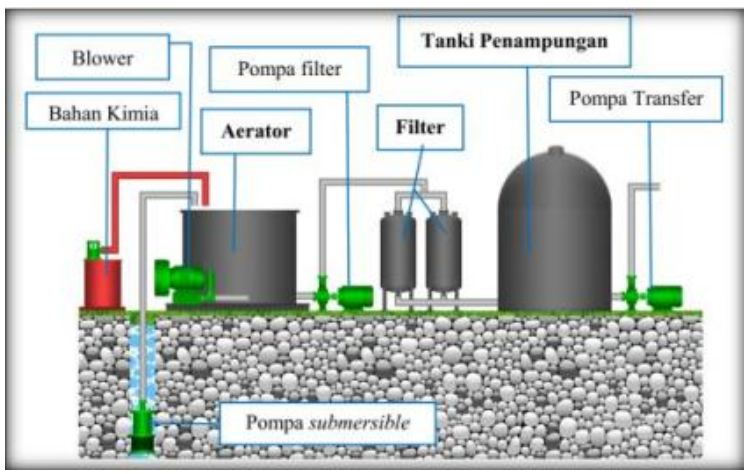

Gambar 1 Unit Pengolah Air Bersih

\section{Aerator}

Aerator adalah suatu alat yang berfungsi untuk tempat terjadinya proses aerasi / oksidasi, dimana air dari sumur ditampung sementara ditangki aerator untuk kemudian dihembuskan udara bertekanan dari blower (kipas peniup). Fungsi dari blower adalah menghembuskan gas-gas yang masuk dan menyempurnakan proses oksidasi. Pemberian udara terhadap air baku yang berasal dari air tanah ini bertujuan agar air baku tersebut terbebas dari berbagai kandungan gas terlarut, seperti amonia $\left(\mathrm{NH}_{3}\right)$, karbon dioksida $\left(\mathrm{CO}_{2}\right)$ dan hidrogen sulfida $\left(\mathrm{H}_{2} \mathrm{~S}\right)$. Melalui proses ini, berbagai gas terlarut tersebut akan terbuang dan keluar ke udara terbuka bersama dengan udara yang keluar dari lubang ventilasi yang terdapat pada aerator [1].

Selain untuk menghilangkan gas-gas terlarut, Proses aerasi juga berfungsi untuk membuat kandungan air menjadi jenuh akan unsur oksigen. Sehingga unsur besi (Fe) dan mangan ( $\mathrm{Mn}$ ) dapat teroksidasi. Unsur besi dan mangan yang sebelumnya memiliki bentuk ferrokarbonat $\left(\mathrm{Fe}^{+2}\right)$ dan ferrosulfat $\left(\mathrm{Mn}^{+2}\right)$, merupakan bentuk yang terlarut di dalam air. Kemudian setelah dilakukan aerasi akan berubah bentuk menjadi ferroksida $\left(\mathrm{Fe}^{+3}\right)$ dan manganoksida $\left(\mathrm{Mn}^{+4}\right)$ yang tidak terlarut di dalam air. Sehingga kedua unsur tersebut menjadi mudah untuk mengendap dan dibuang. Apabila yang masih terbawa oleh air baku, sudah tidak larut lagi dalam air dan akan mudah disaring oleh filter. Reaksi yang terjadi adalah sebagai berikut [1]: $4 \mathrm{Fe}\left(\mathrm{HCO}_{3}\right)_{2}+2 \mathrm{O}_{2} \rightarrow \quad 4 \mathrm{Fe}(\mathrm{OH})_{3}+8 \mathrm{CO}_{2}$ $2 \mathrm{Mn}\left(\mathrm{HCO}_{3}\right)_{2}+\mathrm{O}_{2} \rightarrow 2 \mathrm{MnO}_{2}+4 \mathrm{CO}_{2}+2 \mathrm{H}_{2} \mathrm{O}$
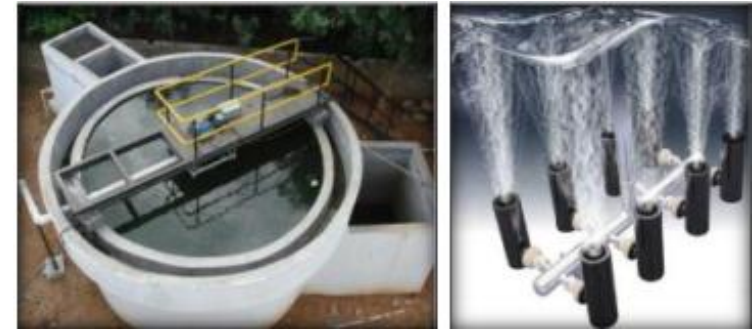

Gambar 2. Aerator

\section{Filter atau Bejana Penyaring}

Filter atau bejana penyaring air digunakan untuk menyaring air dengan bertujuan untuk menahan zat-zat tersuspensi (suspended matter) dalam air dengan metoda melewatkan air tersebut melalui lapisan yang berpori. Air yang telah diaerasi, kemudian disaring dengan tujuan untuk dipisahkan dari partikel-partikel yang tidak dikehendaki. Filter ini dinamai dengan nama Iron Removal Filter (IRF) karena unsur terbesar yang disaringnya adalah unsur besi atau iron $(\mathrm{Fe})$. Filter yang digunakan adalah jenis filter bertekanan (pressurized filter) yang berbentuk bejana simetris dengan media penyaring yang digunakan adalah pasir khusus. [1]

Filter yang telah jenuh akan mempengaruhi kadar besi atau Fe dari air yang keluar. Kadar besi dibatasi maksimal 0,2 ppm. Bila pasir filter telah tertutup oleh kotoran-kotoran, kemampuan menyaring dari pasir filter menjadi berkurang dan konsentrasi besi akan naik dalam air yang keluar filter. Oleh karena itu iron removal filter dilengkapi dengan fasilitas pencucian balik atau backwash, yang digunakan untuk membilas balik filter dari arah yang berlawanan untuk meregenerasi filter agar dapat digunakan kembali

\section{METODA PENELITIAN}

Penelitian ini memiliki dua unit utama yaitu unit pengolah air bersih dan unit sistem kendali, seperti ditunjukkan pada Gambar 3.

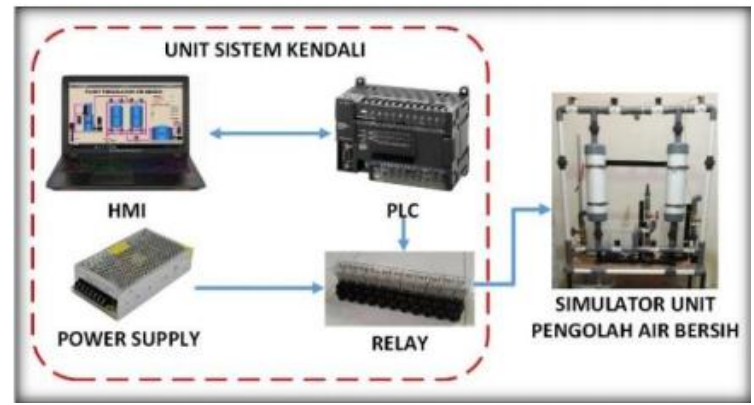

Gambar 3. Diagram unit sistem kendali Iron

Removal Filter (IRF) pada unit pengolahan air bersih 
Secara umum sistem kendali IRF pada unit pengolahan air bersih ini menggunakan PLC yang sebagai pengendali utama. PLC bekerja berdasarkan program yang dipasang di dalamnya dan berdasarkan perintah HMI (Human Machine Interface). HMI sendiri dioperasikan oleh operator yang menjalankan sistem sesuai dengan kebutuhan. Selain PLC dan HMI, unit sistem kendali juga memiliki power supply atau catu daya sebagai sumber daya unit dan serangkaian relai yang mendrive daya dari power supply untuk dikirim menuju peralatan unit pengolah air bersih.

\section{Unit Pengolah Air Bersih}

Unit pengolah air bersih terbuat dari sistem perpipaan dan peralatan yang terdiri dari rangkaian perpipaan, bejana-bejana, pompa motor, blower, manual valve, dan selenoid valve. Peralatan tersebut berfungsi sebagai elemen terakhir yang bekerja mengeksekusi perintah dari unit sistem kendali sesuai dengan proses yang unit pengolah air bersih. Diagram unit pengolah air bersih ditunjukkan pada Gambar 4 .

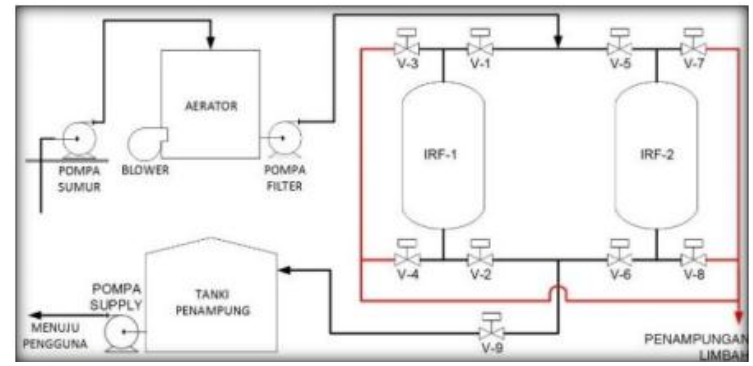

Gambar 4. Sistem Unit Pengolah Air Bersih

\section{Unit Penyaring Iron Removal Filter (IRF)}

Unit Penyaring atau Iron Removal Rilter (IRF) menggunakan sepasang bejana penyaring yang digunakan untuk melakukan proses penyaringan atau filtrasi. Proses ini merupakan penyaringan air dari pengotor yang masih terikut dari proses sebelumnya. Setelah beberapa waktu penyaringan, IRF akan mengalami kejenuhan. Oleh karena itu dilakukan proses regenerasi dengan cara mencuci balik unit penyaring dengan arah yang berlawanan dan dibilas kembali. Siklus dan durasi operasional dari IRF ditunjukkan oleh Gambar 5.

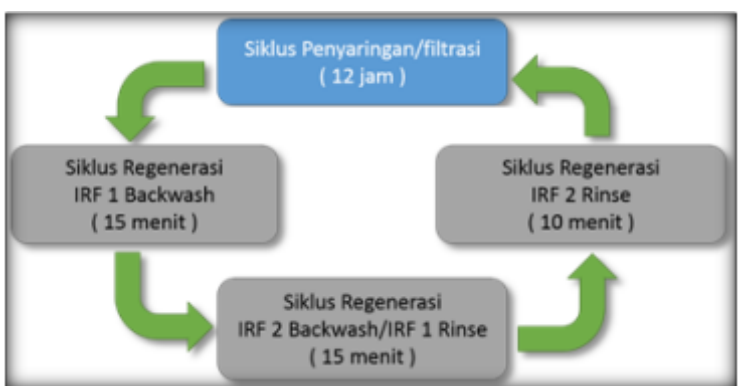

Gambar 5. Diagram Siklus dan Durasi Operasi IRF

Unit IRF dioperasikan dalam tiga mode yang masing-masing dapat diaktifkan menyesuikan dengan keperluan operasional proses pengolahan air bersih yang dilakukan. Mode tersebut terdiri dari:

- Block mode merupakan mode pada saat awal unit IRF akan dioperasikan, pada mode ini semua kerangan dalam posisi tertutup. Block mode juga dapat diaplikasikan pada saat dilakukan perbaikan unit IRF dan mengharuskannya untuk berhenti beroperasi (tidak menyaring air maupun dalam siklus regerasi). Bila terjadi kebocoran atau kondisi darurat, pengaktifan block mode dapat dilakukan sebagai proteksi atau pengaman.

- Manual mode adalah mode dimana operator dapat mengoperasikan posisi setiap kerangan secara manual. Sehingga unit IRF dapat diposisikan ke salah satu posisi yang ada dalam Gambar 6. sesuai dengan kebutuhan.

- Auto Mode adalah mode dimana siklus unit IRF akan berubah menuju siklus selanjutnya secara otomatis. Siklus tersebut dilakukan sesuai urutan waktu pada Gambar 5. dan sesuai posisi kerangan pada Gambar 6. Dalam mode ini operator tidak dapat merubah siklus unit IRF secara manual.

Bila mode diubah oleh operator pada saat auto mode, maka pewaktu atau timer akan berhenti. Bila kembali diposisikan auto mode, maka akan langsung memasuki siklus backwash IRF-1. Hal ini dilakukan dengan tujuan IRF selalu dibersihkan saat pertama kali memasuki auto mode. Sehingga air hasil penyaringan akan selalu dihasilkan dengan kualitas yang baik.

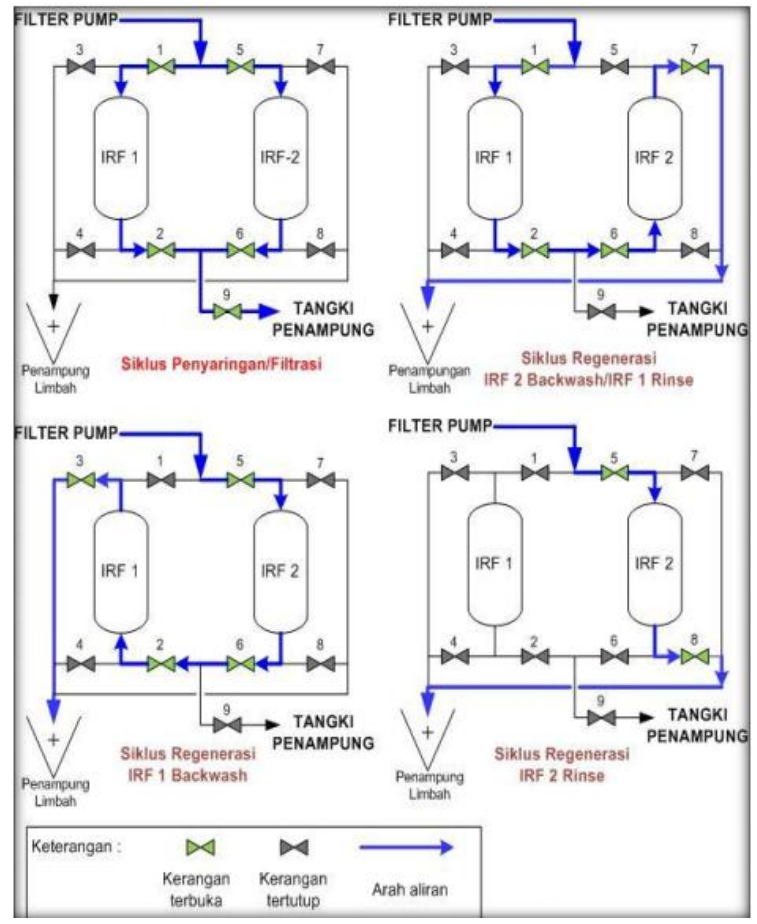

Gambar 6. Diagram Alir dan Konfigurasi Kerangan 


\section{HASIL DAN PEMBAHASAN}

\section{Pompa Sumur (Submersible Pump)}

Sumber air dari unit pengolahan air bersih yang sebenarnya menggunakan air sumur yang berasal dari bawah tanah. Air sumur dipompa oleh sebuah pompa sumur yang terendam (submersible pump) menuju aerator. Air sumur yang sudah dipompa oleh submersible pump disebut dengan air baku. Dalam penelitian ini, digunakan bejana plastik sebagai pengganti sumur, sedangkan sistem submersible pump menggunakan pompa kecil, manual block valve dan jalur pemipaan menuju aerator. Pompa kecil yang digunakan merupakan pompa akuarium yang dipasang terendam di dalam bejana berisi air yang merupakan pengganti sumur. Pompa akuarium ini sesuai desain pada sebuah akuarium dapat dipasang dengan cara direndam seluruh unitnya. Sehingga sangat tepat digunakan sebagai pengganti submersible pump pada sumur yang sebenarnya. Sistem peralatan sumur dan pompa yang dibuat ditunjukkan oleh Gambar 7.

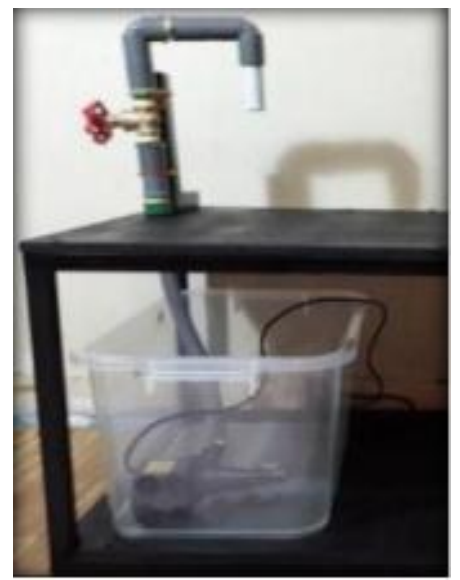

Gambar 7. Rangkaian sistem peralatan sumur dan pompa

\section{Aerator}

Aerator adalah bejana terbuka tempat pertama diolahnya air baku dalam unit pengolahan air bersih. Air baku ditampung dalam sebuah bejana untuk akan dikontakan dengan udara bertekanan yang dihembuskan oleh sebuah penghembus angin atau blower. Proses ini disebut dengan proses aerasi. Kemudian air dalam aerator akan dipompa oleh pompa filter untuk di saring melewati penyaring (Iron Removal Filter). Aerator pada penelitian ini menggunakan sebuah bejana plastik. Sedangkan blower menggunakan penghembus angin kecil untuk akuarium. Pompa filter menggunakan pompa kecil yang dipasang di luar bejana dan semuanya dirangkai dengan sistem perpipaan. Sistem aerator yang dibuat pada penelitian ini ditunjukkan oleh Gambar 8.

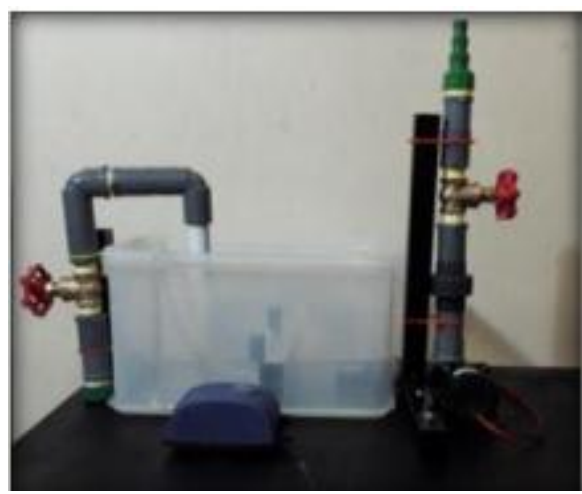

Gambar 8. Rangkaian sistem unit Aerator, Blower, dan Pompa Filter

\section{Unit Penyaring (IRF)}

Unit penyaring atau Iron Removal Filter (IRF) terbuat dari 2 buah bejana filter dan 9 buah solenoid valve dengan supply tegangan 12 VDC dan daya 12 VA. Seluruhnya dirangkai dengan sistem perpipaan menuju tangki penampung. Sistem Iron Removal Filter (IRF) yang dibuat pada penelitian ini ditunjukkan pada Gambar 9.

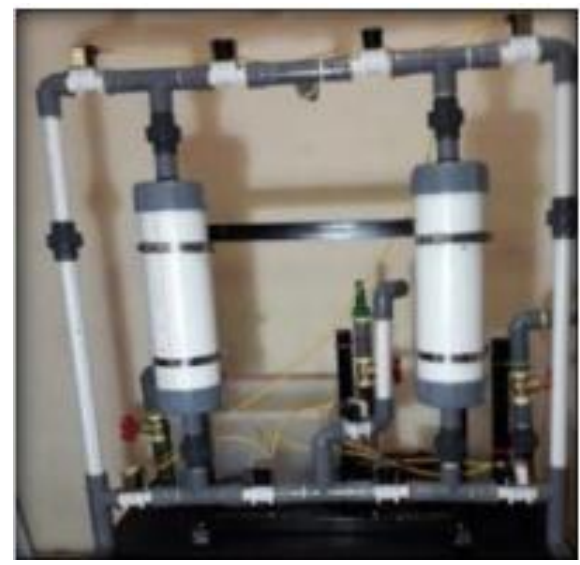

Gambar 9. Unit Iron Removal Filter (IRF)

\section{Tanki Penampungan dan Pompa Supply}

Tangki penampungan air bersih adalah tempat pengumpulan air bersih. Air bersih ditampung untuk selanjutnya dipompa oleh pompa supply menuju konsumen atau pemakai. Unit tangki penampung pada penelitian ini terbuat dari bejana tangki penampung terbuat dari plastik, pompa supply, manual block valve, dan perpipaan yang kemudian dikirimkan ke pemakai air. Pompa supply menggunakan pompa air dengan tegangan supply 12 VDC, daya 19 watt, maksimal laju alir 800 liter/jam dan maksimal daya angkat air setinggi 5 meter. Sistem tangki penampungan dan pompa supply yang dibuat pada penelitian ini ditunjukkan oleh Gambar 10 


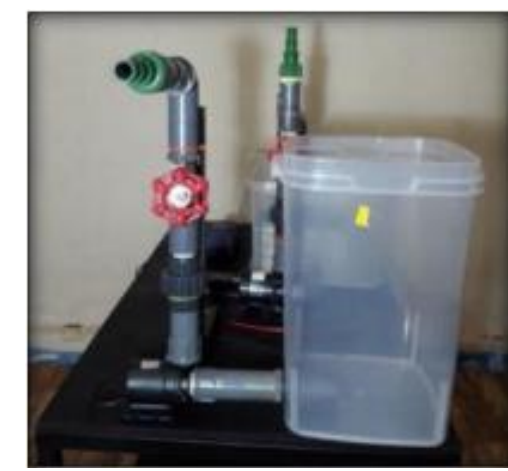

Gambar 10. Unit Tangki dan Pompa Supply

\section{Power Supply (Catu Daya)}

Power supply (catu daya) berfungsi sebagai sumber daya pada berbagai peralatan yang terdapat pada unit pengolahan air bersih dengan perantara sakelarsakelar pada relai. Daya akan diberikan kepada peralatan sesuai dengan dengan energize-nya relai yang diperintahkan oleh PLC. Power supply yang digunakan memiliki input teganan $220 \mathrm{VAC}$ dan output tegangan 12 VDC dengan maksimum beban adalah 30 A. Output tersebut sesuai dengan kebutuhan peralatan dengan maksimum total arus adalah 15,28 A. Diagram penggunaan catu daya pada sistem ditunjukkan oleh Gambar 11.

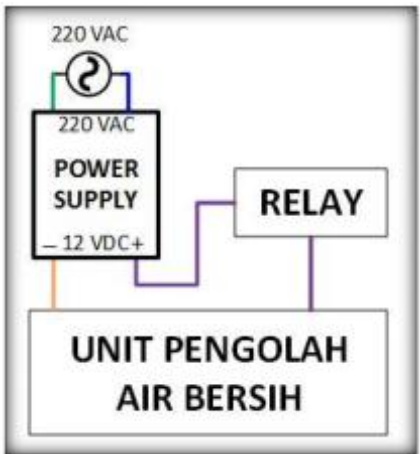

Gambar 11. Power supply pada sistem

\section{Rangkaian Pengaman Catu Daya}

Sekering digunakan sebagai pengaman seluruh rangkaian dari arus berlebih yang bias merusak peralatan di dalam rangkaian. Nilai arus dari sekering merupakan batas maksimum arus yang diperbolehkan memasuki rangkaian. Untuk mendapatkan nilai sekering digunakan dalam penelitian ini, dilakukan perhitungan sebagai berikut:

- Maksimal arus AC pada PLC sesuai spesifikasi adalah sebagai berikut:

$$
I=\frac{P}{V}=\frac{70}{220}=0,318 \mathrm{~A}
$$

Daya maks $(\mathrm{P})$ pada PLC $=70 \mathrm{VA}$

Teganan $(\mathrm{V})$ pada $\mathrm{PLC}=220 \mathrm{VAC}$

- Maksimal arus AC pada pompa motor dan blower bertegangan AC sesuai spesifikasi adalah:

$$
I=\frac{P}{V}=\frac{13+2,5}{220}=0,070455 \mathrm{~A}
$$

Daya maks $(\mathrm{P})$ pada pompa $=13 \mathrm{VA}$ Daya maks $(\mathrm{P})$ pada blower $=2,5 \mathrm{VA}$ Teganan $(\mathrm{V})=220 \mathrm{VAC}$

- Maksimal arus AC pada power supply sesuai spesifikasi:

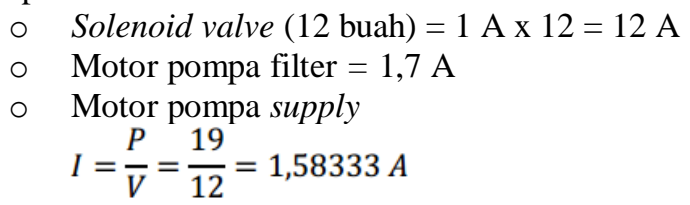

Total arus sekunder pada power supply adalah: $12+1,7+1,58333=15,28333 \mathrm{~A}$

Digunakan persamaan tegangan dan arus transformator:

$$
\begin{array}{ll}
\frac{V p}{V s}=\frac{I s}{I p} & \begin{array}{l}
\mathrm{Vp}=\text { Tegangan primer (Volt) } \\
\text { Vs = Tegangan sekunder (Volt) }
\end{array} \\
\frac{220}{12}=\frac{15,28333}{I p} & \mathrm{Ip}=\text { Arus primer (Ampere) } \\
I p=\frac{15,28333 \times 12}{220} & \\
I p=0,833636 \mathrm{~A}=\text { Arus sekunder (Ampere) } \\
\text { Total arus AC = PLC + Relai + Power Supply } \\
=0,318+0,070455+0,833636 \\
=1,222091 \mathrm{~A}
\end{array}
$$

Sesuai dengan petunjuk penggunaan PLC, maka digunakan sekering dengan nilai 2 kali dari arus yang mengalir $=2 \times 1,222091=2,444182$ A. Maka digunakan sekering dengan nilai $3 \mathrm{~A}$.

\section{Pembuatan Perangkat Lunak}

Perangkat lunak pada sistem kendali Iron Removal Filter (IRF) pada unit pengolahan air bersih berbasis PLC ini meliputi pembuatan program PLC Omron dengan menggunakan software CXprogrammer dan tampilan HMI dengan menggunakan CX-Server OPC dan VTScada. Pembuatan program PLC dilakukan dalam beberapa subroutine program sebagai berikut

- Pump Program. Program untuk menjalankan pompa-pompa dan blower pada unit sistem kendali. Dimana seluruh pompa dan blower dapat dijalankan secara manual. Hanya Pompa-2 atau pompa supply saja yang diproteksi, yaitu hanya bisa berjalan jika salah satu Valve-1 atau Valve-5 ada yang terbuka. Karena kedua kerangan tersebut berada di posisi outlet dari Pompa-2.

- Block Mode Program. Program ini berisi perintah untuk menutup semua kerangan pada unit penyaring IRF-1 dan IRF-2. Mulai dari Valve-1 sampai Valve-9 juga Pompa-2.

- Auto Mode Program. Program ini merupakan program pengendali proses Auto pada unit penyaring IRF-1 dan IRF-2. Mengatur bukaan dan tutupan kerangan Valve-1 sampai Valve-8 dalam waktu tertentu sesuai proses kerja unit penyaring. Pengatur waktunya menggunakan 4 buah fungsi timer "TIM". Masing masing timer digunakan untuk proses service, backwash IRF1, rinse IRF-1 / backwash IRF-2 dan rinse IRF2 . 
- Manual Mode Program. Program ini berfungsi untuk mengoperasikan kerangan pada unit penyaring IRF-1 dan IRF-2. Seluruh kerangan dari Valve-1 sampai Valve-9 dapat dioperasikan secara manual saat mode ini aktif

Sedangkan untuk pembuatan HMI menggunakan perangkat Perangkat Lunak CX-Server OPC dan VTScada. Perangakat Lunak CX-Server OPC berfungsi mengkomunikasikan PLC Omron dan perangkat lunak VTScada pada HMI. Membuat file dengan server project dengan menggunakan CXServer OPC. Dibuat beberapa point untuk seluruh tag baik itu $I / O$, timer, dan Internal Bit yang terdapat pada Program PLC. Hingga seluruh tag telah dibuat point-nya dan dikonfigurasi. Seluruhnya total ada 50 point. VTScada yang digunakan adalah VTScada Light yang memiliki lisensi gratis dengan maksimal penggunaan adalah $50 \mathrm{tag}$. Dengan proses sebagai berikut:

- Membuat Aplikasi VTScada.

- Membuat Port Komunikasi Serial.

- Membuat Driver OPC Client.

- Membuat seluruh I/O tag. Total 50 tag.

- Membuat tampilan HMI.

Hasil tampilan HMI yang dibuat pada penelitian inidapat dilihat pada Gambar 12.

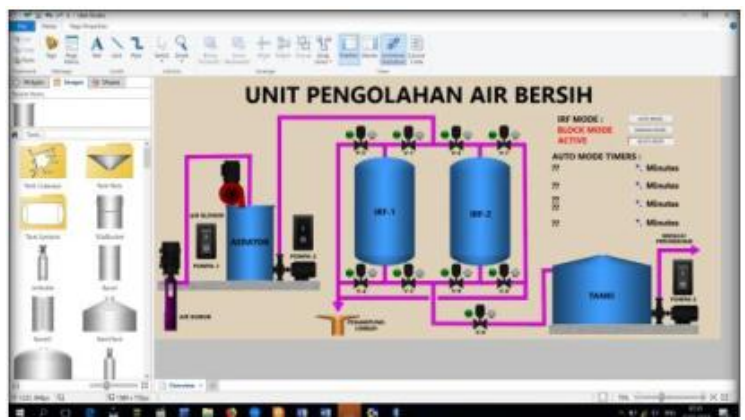

Gambar 12. Hasil tampilan HMI sistem unit pengolahan air bersih

Dan diagram keseluruhan sistem kendali Iron Removal Filter (IRF) pada unit pengolahan air bersih berbasis PLC yang dibuat pada penelitian ini diperlihatkan oleh Gambar 13.

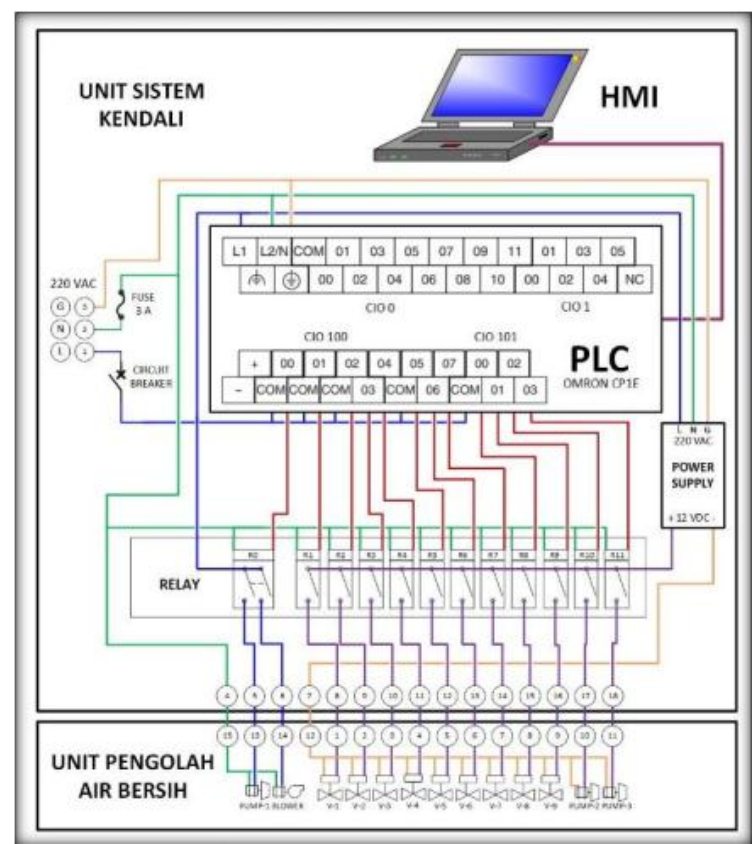

Gambar 13, Diagram sistem kendali Iron Removal Filter (IRF) pada unit pengolahan air bersih berbasis PLC

\section{Pengujian Mode Sistem}

Pengujian mode sistem bertujuan untuk mengetahui kinerja sistem kendali unit pengolah air bersih pada posisi manual, auto dan block mode. Pengujian dilakukan dengan menguji unit sistem kendali yang telah dihubungkan dengan unit pengolah air bersih. Dilakukan pengujian terhadap kinerjanya dalam mengendalikan unit pengolah air bersih dan dalam memberikan perintah berupa pemberian daya kepada seluruh peralatan yang dikendalikan.

\section{Pengujian Manual Mode}

Pada manual mode sistem dioperasikan secara manual melalui HMI, selanjutnya dapat kita ukur arus keluaran (output) dari masing-masing perangkat I/O yang terpasang pada sistem. Hasil pengukuran arus pada output yang terpasang pada sistem diperlihatkan pada Tabel 1.

Tabel 1. Hasil Pengukuran arus pada output sistem

\begin{tabular}{clcc}
\hline No & Mode Operasi & $\begin{array}{c}\text { Output } \\
\text { relai (mA) }\end{array}$ & $\begin{array}{c}\text { Output } \\
\text { device (A) }\end{array}$ \\
\hline 1 & $\begin{array}{l}\text { Pompa Sumur } \\
\text { dan Blower }\end{array}$ & 10,5 & 0,137 \\
2 & Pompa Filter & 10,5 & 1,431 \\
3 & Pompa Supply & 10,3 & 1,299 \\
4 & Valve -1 & 10,57 & 0,445 \\
5 & Valve -2 & 10,72 & 0,46 \\
6 & Valve -3 & 10,43 & 0,447 \\
7 & Valve-4 & 10,3 & 0,472 \\
8 & Valve -5 & 10,66 & 0,46 \\
9 & Valve -6 & 10,63 & 0,447 \\
10 & Valve -7 & 10,56 & 0,44 \\
11 & Valve -8 & 10,63 & 0,472 \\
12 & Valve -9 & 10,41 & 0,471 \\
\hline
\end{tabular}


Dari data pengukuran arus pada coil relai dan pada peralatan unit pengolah air bersih didapatkan perbedaan arus yang cukup besar. Arus dari output PLC yang memberikan daya kepada coil relai tidak lebih dari 10,72 mA, Sedangkan arus yang mengalir dari sakelar relai menuju peralatan unit pengolah air bersih cukup besar, arus ada yang mencapai 1,431 A, Sakelar relai yang berada pada internal output PLC hanya mampu mengalirkan arus maksimal 2A, Sehingga akan sangat beresiko jika output PLC langsung memberikan daya ke peralatan pada unit pengolah air bersih, Penggunaan eksternal relai seperti yang diaplikasikan pada penelitian ini dapat menjadi solusi untuk melindungi PLC dari kerusakan elektronik.

\section{Pengujian Auto Mode}

Pengujian auto mode pada unit penyaringan atau Iron Removal Filter (IRF) terdiri dari beberapa siklus proses yaitu siklus service, IRF-1 backwash, IRF-1 rinse \& IRF-2 backwash, dan siklus IRF-2 rinse. Hasil pengujian siklus proses auto mode dirangkum pada Tabel 2.

Tabel 2. Hasil pengujian auto mode

\begin{tabular}{cll}
\hline No & \multicolumn{1}{c}{ Mode Operasi } & Valve yang aktif \\
\hline 1 & IRF-1 backwash & $2,3,5$ dan 6 \\
2 & IRF-1 rinse \& IRF-2 & $1,2,6$ dan 7 \\
& backwash & \\
3 & IRF-2 rinse & 5 dan 8 \\
4 & Service & $1,2,5,6$ dan 9 \\
\hline
\end{tabular}

Dari hasil pengujian auto mode, output bukaan dan tutupan valve yang dihasilkan peralatan pada setiap siklus telah sesuai dengan program yang dibuat. Waktu perpindahan siklus juga telah sesuai program yang dibuat. Sehingga aliran air terarah sesuai proses dan siklus pada IRF dan operasi proses pada IRF dapat berlangsung dengan baik. Seluruh proses pada auto mode dapat dieksekusi dan proses pada unit pengolah air bersih dapat berlangsung sesuai dengan prinsip kerja unit pengolah air bersih, Sehingga dapat disimpulkan program, rangkaian control board dan unit sistem kendali dapat bekerja dengan baik pada mode ini.

\section{Pengujian Block Mode}

Selanjutnya dilakukan pengujian block mode pada unit penyaringan atau Iron Removal Filter (IRF) dilakukan dan mendapat data yang dirangkum pada Tabel 3.

Dari hasil pengujian terlihat saat perintah block mode diberikan pada HMI, seketika itu juga semua valve pada unit pengolah air bersih langsung menutup dan pompa filter langsung berhenti. Sehingga dapat disimpulkan program, rangkaian control board dan unit sistem kendali dapat bekerja dengan baik saat mode ini.
Tabel 3. Hasil Pengujian Block Mode

\begin{tabular}{clc}
\hline No & \multicolumn{1}{c}{ Output } & \multicolumn{1}{c}{ Kondisi } \\
\hline 1 & Valve -1 & De-energize/menutup \\
2 & Valve -2 & De-energize/menutup \\
3 & Valve -3 & De-energize/menutup \\
4 & Valve -4 & De-energize/menutup \\
5 & Valve -5 & De-energize/menutup \\
6 & Valve -6 & De-energize/menutup \\
7 & Valve -7 & De-energize/menutup \\
8 & Valve -8 & De-energize/menutup \\
9 & Valve- 9 & De-energize/menutup \\
10 & Pompa filter & De-energize/mati \\
\hline
\end{tabular}

\section{KESIMPULAN}

Setelah melalui proses perancangan, pembuatan dan pengujian alat dapat disimpulkan bahwa rancang bangun sistem kendali unit pengolah air bersih berbasis PLC telah dapat berfungsi dengan baik untuk mengendalikan proses pengolahan air bersih pada unit penyaringan atau Iron Removal Filter (IRF) dalam semua mode operasi. Program yang dibuat dalam PLC dapat mengaplikasikan proses kerja IRF ke dalam sistem kendali dan menghasilkan kinerja yang efisien dan efektif karena proses perpindahan siklus berlangsung dengan cepat serta tepat.

Penggunaan VTScada sebagai HMI telah terbukti dapat berkomunikasi dengan PLC sebagai pusat sistem kendali. Hasilnya yaitu dapat memudahkan operator dalam memasukan perintah dan dapat menampilkan kondisi proses dengan lebih baik. Sehingga perintah dapat dikerjakan dengan cepat, tepat dan aman dalam mengoperasikan unit pengolah air bersih.

Setelah dilakukan pengujian terhadap manual mode, auto mode, dan block mode, dapat diambil kesimpulan bahwa seluruh program yang dibuat dalam PLC telah sesuai dengan prinsip kerja unit pengolah air bersih.

\section{DAFTAR PUSTAKA}

1. Siemens. 2007. Siemens PLC ebook. Buku Elektronik. Siemens AG

2. Omron Corporation. 2008. CX-Server OPC User Manual Getting Started Version 2.0.

3. PT Badak NGL. Bontang. 2014. Water Treatment Plant (Plant-36/48/49) Utilities Manual Book.

4. Trihedral Engineering Limited. 2016. VTScada Developer's Guide.

5. Omron Corporation. 2017. SYSMAC CP-Series CP1E CPU Unit Hardware User's Manual

6. Bolton, William. 2003. Programmable Logic Controller (PLC) Sebuah Pengantar Edisi Ketiga. Erlangga. Jakarta.

7. Hasan. 1998. Optimasi Reaktifitas pada Sistem Pengaturan Daya Reaktor Zero Power dengan 
Persamaan Hamilton Pontryagin. Tesis. FMIPA. ITB. Bandung

8. Jack, Hugh. (2007). Automating Manufacturing System with PLCs. Versi 5.0. Buku Elektronik. NU Free Documentation License

9. Kho, Dickson. 2017. Pengertian Relay dan Fungsinya Teknik Elektronika. https://teknikelektronika.com/pengertianrelayfun gsi-relay/. Diakses 2 Februari 2019. 